\title{
The Market Reaction Around Ex-Dates of Stock Splits Before and After Decimalization
}

\author{
Robin K. Chou \\ Department of Finance, National Central University \\ Jhongli City, Taoyuan, Taiwan, R.O.C. \\ rchou@cc.ncu.edu.tw

\section{Wan-Chen Lee} \\ Department of Finance, Ching Yun University \\ Jhongli City, Taoyuan, Taiwan, R.O.C. \\ wanchenlee@mail.cyu.edu.tw

\section{Sheng-Syan Chen} \\ Department of Finance, National Taiwan University \\ Taipei, Taiwan, R.O.C. \\ fnschen@management.ntu.edu.tw
}

This paper examines the stock price behavior around the ex-split dates both before and after the decimalization on the New York Stock Exchange (NYSE). We find that the abnormal ex-split day returns decrease and the abnormal trading volume increases in the $1 / 16$ th and decimal pricing eras, relative to the $1 / 8$ th pricing era. These findings are consistent with the microstructure-based explanations for the ex-day price movements. Our study also supports the hypothesis that short-term traders perform arbitrage activities during the ex-split dates when transaction costs become lower after the tick size is reduced.

Keywords: Stock splits; decimalization; ex-dates.

\section{Introduction}

In a perfect market, the expected price adjustment on the ex-distribution day of a stock split is the last closing price prior to the ex-date divided by one plus the factor to adjust the price. ${ }^{1}$ However, market imperfections, such as

\footnotetext{
${ }^{1}$ For a stock dividend or a split, the factor to adjust price is the number of additional shares per old share issued.
} 
the existence of the tick size, transactions costs and taxes, may prohibit full price adjustment on the ex-date. A considerable number of empirical studies reveal that stock prices do not fully adjust on those days when the stock splits take effect. Such studies (Woolridge, 1983; Eades, Hess and Kim, 1984; Grinblatt, Masulis and Titman, 1984; Lamoureux and Poon, 1987; Maloney and Mulherin, 1992; Conrad and Conroy, 1994; Dhatt, Kim and Mukherji, 1997; Bali and Hite, 1998; and others) have documented statistically significant abnormal ex-date returns for stock dividends and stock splits. What, then, are the determinants of the abnormal returns on the ex-split days? Previous studies (Grinblatt, Masulis and Titman, 1984; Lamoureux and Poon, 1987; Maloney and Mulherin, 1992; Conrad and Conroy, 1994; Bali and Hite, 1998; and others) have put forth the view that the abnormal return on the ex-split day may be caused by microstructure effects. ${ }^{2}$ In this study, we directly test the microstructure effects in order to explain the ex-split day price-drop puzzle. We investigate the abnormal returns and trading volume around the ex-split days both before and after the US stock market switched to decimal quotations.

Grinblatt, Masulis and Titman (1984) first argue that the ex-day price movements are tied to the market microstructure phenomenon. They claim that specialists' inventory practices lead to an excess of trades at bid prices on the day preceding the split, which results in obvious abnormal returns on the ex-day that merely represent the movement from bid to ask prices. Lamoureux and Poon (1987) show that the positive return following the ex-day comes from price pressures related to an increase in the number of stockholders subsequent to the split. By modifying Lamoureux and Poon's argument and incorporating Grinblatt, Masulis and Titman's conjectures on the market microstructure, Maloney and Mulherin (1992) argue that the increase in shareholders may lead to temporary order imbalances that induce a concentration of orders at ask prices and give rise to abnormal returns. They present evidence showing that closing prices both on and after the split ex-dates tend to cluster at ask prices.

Motivated by the fact that a substantial fraction of stock purchases are single or small round lot orders, Conrad and Conroy (1994) conjecture that post-split orders consist of numerous small buyers and a few large sellers. This change in order flow causes closing prices to occur more frequently at the ask price, which is consistent with Maloney and Mulherin. Bali and Hite

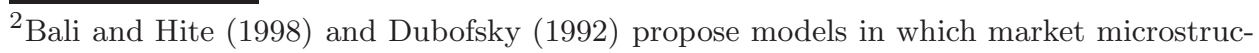
ture effects play a role in the ex-dividend day price drop anomaly. 
(1998) argue that the price-drop ratio deviates from one because of price discreteness. They claim that the ex-day price of a stock will change by a price increment that is equal to, or just smaller than, the size of the dividend payment. $^{3}$

If abnormal returns on the ex-split day are caused mainly by the microstructure effects (especially the order imbalances) mentioned above, it is expected that the anomaly will likely to disappear as the tick size (herein the bid-ask spreads) become smaller. ${ }^{4}$ The recent change in the NYSE's quoting mechanism provides us with an opportunity to examine our conjectures. By the end of January 2001, all NYSE stocks had converted their price quotations from one-eighth $(1 / 8 \mathrm{~s})$ and one-sixteenth $(1 / 16 \mathrm{~s})$ to decimals. Decimal pricing was one of the most dramatic changes in the US quoting system, and it largely reduced the tick size and bid-ask spread. If the bid-ask spread is significantly reduced, it will dilute the effects of price clustering from bid to ask during the ex-date period. On the other hand, positive ex-day returns may attract short-term traders, who in turn may eliminate the positive returns up to their marginal transaction costs (Karpoff and Walkling, 1988).

With a smaller bid-ask spread (i.e., lower transaction costs), short-term traders may find it more profitable to enter the market, which will further arbitrage away abnormal returns on ex-split days. We thus conduct direct empirical tests of the impact of changes in tick size on the ex-split day price and trading behavior. ${ }^{5}$ Our goal is to provide a better understanding of the impact of decimalization on nontaxable ex-distribution day abnormal returns, and to shed light on whether a microstructurebased explanation is important for explaining the ex-date pricing of stock splits.

Our study differs from previous studies in the following ways. First, we perform a direct test of the relationship between price discreteness and exsplit day abnormal returns. To the best of our knowledge, there is no study

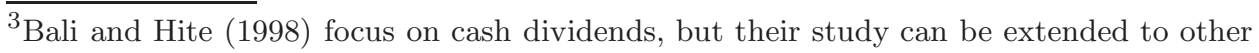
distribution events such as stock dividends or stock splits.

${ }^{4}$ Quoted and effective spreads reductions due to changes in the tick size are well documented in the literature (Bollen and Whaley, 1998; Gibson, Singh and Yerramilli, 2003; and others).

${ }^{5}$ Recently, Graham, Michaely and Roberts (2003) and Jakob and Ma (2004) examined the cum- to ex-cash dividend day price drops during the one-eighth, one-sixteenth and decimal tick regimes. They found no significant decline in the magnitude of the ex-day anomaly following the reduction in the tick size.
} 
that focuses on the ex-split day stock price behavior both before and after decimalization. Because of the different attributes between stock splits and cash dividends, it is worth examining whether the tick sizes have different impacts on stock splits. Secondly, stock splits are tax irrelevant. Thus, by focusing on nontaxable distribution events, the complex impact of the US tax code on ex-day returns can be dropped. Furthermore, to test the proposition that short-term arbitrage trading on ex-split days will be more intensive after decimalization, we also investigate the trading volume surrounding the ex-split day. The influence of short-term traders on ex-day security prices can be more clearly demonstrated by simultaneously examining the trading volume around the ex-day (Lakonishok and Vermaelen, 1986).

Our empirical results indicate that, in the era characterized by a smaller tick size and bid-ask spread (i.e., lower transaction costs), the ex-day abnormal returns are closer to zero and the abnormal volume is significantly positive on both the ex-day and the day before the ex-day. In the era with a larger tick size and bid-ask spread (i.e., higher transaction costs), the ex-day abnormal returns are significantly positive and the ex-day abnormal trading volume is insignificantly different from zero. Such results show that the tick size plays an important role in ex-split day returns. That is, the market microstructure effects could serve to explain the ex-date price-drop puzzle for stock splits. Our study also provides evidence of higher intensity of short-term trading around the ex-split days following decimalization.

The remainder of this paper is organized as follows. Section 2 develops the hypotheses tested in this paper. Section 3 describes the data and explains the research methodology. Section 4 presents the empirical results and Sec. 5 concludes.

\section{Testable Implications}

The US markets have over the years provided a natural experiment to examine how important a role the market microstructure factors play in ex-split day abnormal returns. Since 2001, tick size and bid-ask spreads have fallen dramatically, allowing us to test the microstructure-based explanations. In much the same spirit as in previous studies, the basic prediction of the microstructure theories is that this decline in the minimum tick size and the associated reduction in the bid-ask spread should decrease the average ex-day abnormal return, and make it closer to zero after decimalization. On the other hand, higher transaction costs during the fraction quotation era may prevent short-term traders from entering the market to squeeze out microstructure-induced abnormal returns. After decimalization, lower 
transaction costs will facilitate short-term arbitrages around the ex-split day, which will cause the ex-day abnormal returns to disappear.

Hypothesis 2.1. During the decimal pricing era, the ex-split day abnormal returns are smaller than those of the one-eighth or onesixteenth era and become closer to zero.

Lakonishok and Vermaelen (1986) pointed out that price reaction studies were unable to discriminate between the various hypotheses concerned with ex-day price behavior. They argued that the influence of short-term traders on ex-day security prices can be more clearly demonstrated by examining trading volume, in which case the presence of short-term traders influencing ex-day security pricing would be revealed through positive abnormal volume around the ex-day. Lakonishok and Vermaelen (1986), Shaw (1991) and Graham, Michaely and Roberts (2003) all present evidence of unusual volume patterns around the ex-cash dividend days, a finding that is consistent with short-term trading activity. After decimalization, as transaction costs fall, we expect that more short-term traders will enter the market, so that trading volume will increase.

Hypothesis 2.2. As transaction costs fall after reductions in tick size, the ex-split day abnormal trading volume will increase.

\section{Sample Selection and Research Methodology}

\subsection{Sample selection}

Following Graham, Michaely and Roberts (2003), our study compares the ex-split returns and volumes during the last part of the $1 / 8$ th pricing era (January 1, 1996 to May 6, 1997) with those during the 16th pricing era (June 24, 1997 to August 26, 2000) as well as with those during the decimal pricing era (January 29, 2001 to December 31, 2002). We examine NYSE firms that execute a stock distribution of at least $25 \%$ to their common shares, as indicated by the Center for Research in Security Prices (CRSP) distribution codes 5523 or $5533 .{ }^{6}$ We obtain daily closing prices, distribution information, volume (number of shares traded, in shares) and shares outstanding (recorded in thousands) from the CRSP database.

In selecting the stock splits sample, we follow Eades, Hess and Kim (1984) and Maloney and Mulherin (1992). First, we exclude all distributions

\footnotetext{
${ }^{6}$ Typically, researchers (Grinblatt, Masulis and Titman, 1984; Lamoureux and Poon, 1987; Maloney and Mulherin, 1992; and others) have used the CRSP classification or have adopted a rule of thumb classifying all distributions of $25 \%$ or more as stock splits.
} 
having any other event announcements, especially dividend announcement or other ex-dividend days within a period of five days on either side of the sample ex-days. ${ }^{7}$ Second, we delete all reoccurrences of splits in our study period to ensure independent observations. For the remaining sample, we delete the firms that have less than 100 days of non-missing returns data over the estimation period, which is from 310 days to 61 days prior to the split ex-day. After these screening processes, the final sample consists of 724 splits.

Table 1 presents the sample characteristics. Panel A shows the sample distribution for each calendar year. There are fewer events in more recent

Table 1. Sample distributions of stock splits.

This table summarizes the sample distributions of splitting firms with a split factor of 1.25 for 1 or more from 1996 to 2002. Only common stocks are included. The following sample selection criteria are used: (1) Shares of splitting firms are listed on the NYSE; (2) The initial ex-split date needs to be clearly identifiable in the CRSP; (3) The splitting firms must have daily stock price information available from the CRSP database; (4) There are no other event announcements or executions five days before or five days after the ex-split day. The $1 / 8$ th era is from January 1, 1996 to May 6, 1997. The 1/16th era is from June 24, 1997 to August 26, 2000. The decimal era is from January 29, 2001 to December 31, 2002. Numbers in parentheses in Panel C are medians.

\begin{tabular}{|c|c|c|}
\hline Year & Number of Stock Splits & Percentage of Sample \\
\hline \multicolumn{3}{|c|}{ Panel A: Sample Distribution by Calendar Year } \\
\hline 1996 & 138 & 19.06 \\
\hline 1997 & 188 & 25.97 \\
\hline 1998 & 178 & 24.59 \\
\hline 1999 & 77 & 10.64 \\
\hline 2000 & 44 & 6.08 \\
\hline 2001 & 53 & 7.32 \\
\hline 2002 & 46 & 6.35 \\
\hline Total & 724 & 100.00 \\
\hline Period $\quad$ Era & Number of Stock Splits & Percentage of Sample (\%) \\
\hline \multicolumn{3}{|c|}{ Panel B: Sample Distribution by Era } \\
\hline 1996/01/01-1997/05/06 1/8th & 182 & 25.14 \\
\hline 1997/06/24-2000/08/26 1/16th & 443 & 61.19 \\
\hline 2001/01/29-2002/12/31 Decimal & 99 & 13.67 \\
\hline Total & 724 & 100.00 \\
\hline
\end{tabular}

${ }_{7}$ The sample was checked for contamination by examining earnings and investment announcements, dividend announcements, announcements of new issues, redemptions or repurchases of securities, mergers, acquisitions, exchange offers, reorganizations and impending bankruptcy on the Wall Street Journal (WSJ) Ondisc database. 
Table 1. (Continued)

\begin{tabular}{|c|c|c|c|c|}
\hline Period & Era & $\begin{array}{l}\text { Stock Price Before } \\
\text { the Ex-day }\left(P_{t-1}\right)\end{array}$ & $\begin{array}{l}\text { Stock Price on } \\
\text { the Ex-day }\left(P_{t}\right)\end{array}$ & Split Factor \\
\hline \multicolumn{5}{|c|}{ Panel C: Descriptive Statistics of the Sample } \\
\hline 1996/01/01-1997/05/06 & $1 / 8$ th & $\begin{array}{c}58.35 \\
(52.75)\end{array}$ & $\begin{array}{c}30.82 \\
(28.44)\end{array}$ & $\begin{array}{c}0.87 \\
(1.00)\end{array}$ \\
\hline $1997 / 06 / 24-2000 / 08 / 26$ & $1 / 16$ th & $\begin{array}{c}68.12 \\
(62.75)\end{array}$ & $\begin{array}{c}35.52 \\
(32.81)\end{array}$ & $\begin{array}{c}0.90 \\
(1.00)\end{array}$ \\
\hline $2001 / 01 / 29-2002 / 12 / 31$ & Decimal & $\begin{array}{c}61.51 \\
(58.60)\end{array}$ & $\begin{array}{c}34.78 \\
(33.78)\end{array}$ & $\begin{array}{c}0.77 \\
(1.00)\end{array}$ \\
\hline
\end{tabular}

years. Panel B presents the sample distribution by three different pricequoting systems. Of the total of 724 observations, 182 observations are in the 1/8th era, 443 observations are in the 1/16th era, and 99 observations are in the decimal pricing era. The average (median) stock price on the day immediately prior to the ex-split day is $\$ 58.35$ (\$52.75) during the $1 / 8$ th price-quoting system, $\$ 68.12(\$ 62.75)$ during the $1 / 16$ th price-quoting system and $\$ 61.51$ ( $\$ 58.60)$ during the decimal price-quoting system. The mean (median) stock price on the ex-split day is $\$ 30.82(\$ 28.44)$ during the $1 / 8$ th price-quoting system, $\$ 35.52(\$ 32.81)$ during the $1 / 16$ th price-quoting system and $\$ 34.78$ (\$33.78) during the decimal price-quoting system. The mean split factor of 0.87 during the $1 / 8$ th era is similar to the mean split factor of 0.90 during the $1 / 16$ th era. The mean split factor of 0.77 after decimalization is smaller than the previous two periods.

\subsection{Research methodology}

We employ an event-study type approach. Measures of returns (including raw returns and abnormal returns) and trading activities surrounding exsplit dates both before and after a new quoting system are implemented. We first calculate returns and trading volume for the three sample periods (i.e., 1/8th, 1/16th and decimal regimes) for each stock, and then compute the cross-sectional mean and standard deviation. The statistics of the standard $t$-test for mean returns are reported.

\subsubsection{Raw return}

On the ex-split day, the daily raw returns $\left(r_{t}\right)$ are computed as the following:

$$
r_{t}=\left(P_{t}(1+f) / P_{t-1}\right)-1,
$$


where $P_{t}$ is the closing price on the ex-date, $P_{t-1}$ is the closing price on the day prior to the ex-date and $f$ is the split factor.

\subsubsection{Market index-adjusted abnormal return}

Market index-adjusted abnormal returns are defined as a stock's raw returns less the CRSP value-weighted market index.

\subsubsection{Abnormal returns by the Fama-French three-factor market model}

Abnormal returns are also calculated using the Fama-French three-factor model estimated over an estimation period of 250 days beginning 61 days before the ex-day. ${ }^{8}$ Observations are required to have a minimum of 100 non-missing returns during this period. We estimate the Fama-French threefactor market model for each security $i$ as follows:

$$
r_{i t}=b_{0}+b_{1} R P_{t}+b_{2} S M B_{t}+b_{3} H M L_{t}+e_{t},
$$

where $r_{i t}$ is the return for security $i$ in excess of the risk-free rate on day $t$, $R P$ is the excess return on the market portfolio, $S M B$ is the return on a factor portfolio capturing the size factor, and the $H M L$ captures the bookto-market factor. The definitions of $S M B$ and $H M L$ are the same as those in Fama and French (1993).

\subsubsection{Trading volume}

In addition to the ex-split day returns, we calculate the turnover ratio to examine the trading activity during the 11-day event window surrounding the ex-split day. The turnover ratio is the aggregate number of shares traded on a given day divided by the number of outstanding shares. The normal volume for an event is computed by finding the average daily turnover for the 80 days from day -45 to 45 (relative to the ex-split day), excluding 5 days before and after the ex-day. ${ }^{9}$ The abnormal volume for each day in the

\footnotetext{
${ }^{8}$ We wish to thank Kenneth French for supplying the portfolio returns on his website. The construction of these data is described in Fama and French (1993).

${ }^{9}$ This treatment follows Graham, Michaely and Roberts (2003).
} 
event window is computed by taking the ratio of turnover for that day to normal turnover and subtracting one. The equation is as follows:

$$
A V_{t}=\left(T O_{t} / \overline{T O}\right)-1,
$$

where $T O_{t}$ is the aggregate number of shares traded on a given day divided by the number of outstanding shares on day $t$, and $\overline{T O}$ is the average daily turnover for the 80 days from day -45 to 45 (relative to the ex-split day), excluding 5 days before and after the ex-day. The cumulative abnormal volume for a given day is the sum of the abnormal volume from the preceding days in the event window.

\section{Empirical Results}

\subsection{Stock price reactions around ex-split days}

Traders' reactions on the ex-day may affect trading decisions immediately before and after the ex-day and, therefore, the returns on these days (Kadapakkam, 2000). Table 2 presents the raw returns and cumulative raw returns during the 11-day period surrounding the ex-split day in the three different regimes of tick size. The ex-day mean raw returns are $0.84 \%$ in the $1 / 8$ th era and $0.52 \%$ in the $1 / 16$ th era, respectively, and both are significant. In contrast, the raw return on the ex-day in the decimal era is $0.25 \%$, which is smaller and insignificant. The cumulative raw returns in the first two ears are all significant, but none of the cumulative raw returns in the decimal era is significant. These results provide support for Hypothesis 2.1 that the ex-day returns should decrease as the tick size and hence the bid-ask spread decrease.

Table 3 shows the market index adjusted abnormal returns around the ex-split day in the three different tick size regimes. The mean abnormal returns are $0.79 \%$ in the $1 / 8$ th era and $0.32 \%$ in the $1 / 16$ th era, respectively. Both abnormal returns are significant. However, the abnormal return in the decimal era is smaller at $0.15 \%$ and insignificant. The results for cumulative abnormal returns are similar to those for the abnormal returns, where none of the cumulative abnormal returns is significant in the decimal era.

Table 4 presents the abnormal returns obtained by the Fama and French three-factor model on the ex-split day during the three different pricing eras. ${ }^{10}$ The mean abnormal returns are significant at $0.75 \%$ in the $1 / 8$ th

\footnotetext{
${ }^{10}$ We also employ the simple market model to estimate the abnormal returns. The results are qualitatively similar and available upon request.
} 
Table 2. Cumulative raw returns around the ex-split day for NYSE-listed stocks by era, 1996-2002.

This table presents the raw returns and cumulative stock returns surrounding the executions of 724 stock splits from 1996 to 2002 according to the different price-quoting eras. The $1 / 8$ th era extends from January 1, 1996 to May 6, 1997, the 1/16th era from June 24, 1997 to August 26, 2000, and the decimal era from January 29, 2001 to December 31, 2002. For each day relative to the ex-split day (day 0), individual raw returns are averaged across the splitting securities in the sample for that day. The cumulative abnormal return is the sum of the abnormal volumes up to and including that day. "***", "*** and "** denote significance levels of $1 \%, 5 \%$ and $10 \%$, respectively, for the $t$-test.

\begin{tabular}{cccr}
\hline & $\begin{array}{c}1 / 8 \text { th Era } \\
(1996 / 01 / 01-\end{array}$ & $\begin{array}{c}1 / 16 \text { th Era } \\
(1997 / 06 / 24-\end{array}$ & $\begin{array}{r}\text { Decimal Era } \\
(2001 / 01 / 29\end{array}$ \\
Event Day & $1997 / 05 / 06)$ & $2000 / 08 / 26)$ & $2002 / 12 / 31)$ \\
\hline Panel A: Raw Returns & & \\
-5 & 0.0009 & 0.0017 & 0.0004 \\
-4 & 0.0002 & 0.0003 & -0.0019 \\
-3 & -0.0005 & $0.0018^{*}$ & -0.0001 \\
-2 & -0.0003 & 0.0005 & -0.0017 \\
-1 & 0.0028 & $0.0043^{* * *}$ & -0.0029 \\
0 & $0.0084^{* * *}$ & $0.0052^{* * *}$ & 0.0025 \\
1 & $0.0057^{* *}$ & 0.0005 & -0.0024 \\
2 & 0.0019 & -0.0013 & 0.0018 \\
3 & 0.0020 & -0.0001 & -0.0008 \\
4 & $-0.0037^{*}$ & -0.0001 & -0.0019 \\
5 & 0.0006 & $-0.0043^{* * *}$ & 0.0015 \\
Panel B: Cumulative Raw Returns & & \\
$(-1,0)$ & $0.0112^{* * *}$ & $0.0095^{* * *}$ & -0.0004 \\
$(0,1)$ & $0.0141^{* * *}$ & $0.0057^{* *}$ & 0.0000 \\
$(-1,1)$ & $0.0169^{* * *}$ & $0.0099^{* * *}$ & -0.0031 \\
$(-2,2)$ & $0.0185^{* * *}$ & $0.0091^{* * *}$ & -0.0028 \\
\hline
\end{tabular}

era, and significant at $0.28 \%$ in the $1 / 16$ th era. In contrast, none of the abnormal returns are significant in the decimal era. In the $1 / 8$ th era, all the cumulative returns are significant. The significance of cumulative returns reduces greatly in the $1 / 16$ th era and disappears entirely in the decimal era.

These results are consistent with Hypothesis 2.1 that as the bid-ask spread decreases, the ex-split day abnormal returns should become smaller. Such results also support the hypothesis that the potential for short-term trading enabled by decimalization should reduce the ex-split day returns, since the profits for short-term trading are increased as the transaction costs 
Table 3. Cumulative abnormal returns (market index-adjusted) around the ex-split day for NYSE-listed stocks by era, 1996-2002.

This table presents the (cumulative) abnormal returns surrounding the executions of 724 stock splits from 1996 to 2002 according to the different price-quoting eras. The $1 / 8$ th era extends from January 1 , 1996 to May 6, 1997, the 1/16th era from June 24, 1997 to August 26, 2000, and the decimal era from January 29, 2001 to December 31, 2002. Abnormal returns are individual stock returns less market index returns. The CRSP value-weighted index is used as a proxy for the market index. For each day relative to the ex-split day (day 0), individual abnormal returns are averaged across the splitting securities in the sample for that day. The cumulative abnormal return is the sum of the abnormal volumes up to and including that day. "***", "***" and "*" denote significance levels of $1 \%, 5 \%$ and $10 \%$, respectively, for the $t$-test.

\begin{tabular}{|c|c|c|c|}
\hline Event Day & $\begin{array}{c}1 / 8 \text { th Era } \\
(1996 / 01 / 01- \\
1997 / 05 / 06)\end{array}$ & $\begin{array}{c}\text { 1/16th Era } \\
(1997 / 06 / 24- \\
2000 / 08 / 26)\end{array}$ & $\begin{array}{c}\text { Decimal Era } \\
(2001 / 01 / 29 \\
2002 / 12 / 31)\end{array}$ \\
\hline \multicolumn{4}{|c|}{ Panel A: Abnormal Returns } \\
\hline-5 & 0.0001 & 0.0014 & 0.0023 \\
\hline-4 & 0.0001 & -0.0002 & -0.0004 \\
\hline-3 & 0.0009 & $0.0016^{*}$ & 0.0007 \\
\hline-2 & -0.0012 & 0.0008 & -0.0011 \\
\hline-1 & $0.0032^{*}$ & $0.0020^{*}$ & -0.0020 \\
\hline 0 & $0.0079^{* * *}$ & $0.0032^{*}$ & 0.0015 \\
\hline 1 & $0.0042^{*}$ & -0.0007 & 0.0019 \\
\hline 2 & 0.0014 & -0.0015 & 0.0028 \\
\hline 3 & 0.0022 & -0.0014 & -0.0007 \\
\hline 4 & $-0.0042^{* *}$ & -0.0008 & 0.0004 \\
\hline 5 & 0.0001 & $-0.0048^{* * *}$ & 0.0026 \\
\hline \multicolumn{4}{|c|}{ Panel B: Cumulative Abnormal Returns } \\
\hline$(-1,0)$ & $0.0110^{* * *}$ & $0.0052^{* * *}$ & -0.0005 \\
\hline$(0,1)$ & $0.0121^{* * *}$ & 0.0025 & 0.0034 \\
\hline$(-1,1)$ & $0.0152^{* * *}$ & $0.0045^{*}$ & 0.0013 \\
\hline$(-2,2)$ & $0.0155^{* * *}$ & 0.0039 & 0.0029 \\
\hline
\end{tabular}

are lower in the decimal pricing system. That is, our evidence supports the argument that price discreteness is an important factor in explaining the anomalous ex-split day stock price behavior.

\subsection{Trading volume reactions around ex-split days}

Except for examining the ex-split day stock returns, we also check the ex-split day trading volume to directly test Hypothesis 2.2. Table 5 presents the changes in the turnover ratios around the ex-split day in the three 
Table 4. Cumulative abnormal returns (Fama and French threefactor model) around the ex-split day for NYSE-listed stocks by era, 1996-2002.

This table presents the (cumulative) abnormal returns surrounding the executions of 724 stock splits from 1996 to 2002 according to the different price-quoting eras. The $1 / 8$ th era extends from January 1, 1996 to May 6, 1997, the 1/16th era from June 24, 1997 to August 26, 2000, and the decimal era from January 29, 2001 to December 31, 2002. Abnormal returns are estimated using the Fama and French three-factor market model procedure with parameters estimated over a control period of 250 days beginning 61 days before the ex-split day (day 0 ). For each day relative to the ex-split day, individual abnormal returns are averaged across the splitting securities in the sample for that day. The cumulative abnormal return is the sum of the abnormal volumes up to and including that day. "***", "***" and "** denote significance levels of $1 \%, 5 \%$ and $10 \%$, respectively, for the $t$-test.

\begin{tabular}{cccc}
\hline & $1 / 8$ th Era & $1 / 16$ th Era & $\begin{array}{c}\text { Decimal Era } \\
(2001 / 01 / 29\end{array}$ \\
Event Day & $1996 / 01 / 01-$ & $(1997 / 06 / 24-$ & $2002 / 12 / 31)$ \\
\hline Panel A: Abnormal Returns & & \\
-5 & -0.0014 & 0.0010 & 0.0012 \\
-4 & -0.0004 & -0.0008 & -0.0023 \\
-3 & -0.0008 & 0.0007 & -0.0010 \\
-2 & -0.0015 & -0.0004 & -0.0027 \\
-1 & 0.0025 & 0.0007 & -0.0027 \\
0 & $0.0075^{* * *}$ & $0.0028^{*}$ & -0.0018 \\
1 & 0.0024 & -0.0016 & -0.0008 \\
2 & -0.0001 & -0.0025 & 0.0013 \\
3 & 0.0021 & -0.0021 & -0.0017 \\
4 & $-0.0041^{* *}$ & -0.0016 & -0.0009 \\
5 & -0.0007 & $-0.0050^{* * *}$ & 0.0019 \\
Panel B: Cumulative Abnormal Returns & \\
$(-1,0)$ & $0.0101^{* * *}$ & $0.0035^{*}$ & -0.0045 \\
$(0,1)$ & $0.0099^{* * *}$ & 0.0013 & -0.0026 \\
$(-1,1)$ & $0.0124^{* * *}$ & 0.0020 & -0.0053 \\
$(-2,2)$ & $0.0108^{* * *}$ & -0.0009 & -0.0066 \\
\hline
\end{tabular}

quoting systems. The results indicate that the trading volume is greater surrounding the ex-split day. If transaction costs are an obstacle to the exsplit arbitrage trading, the reduction in the bid-ask spread due to changes in minimum tick size should lead to an increase in the abnormal volume. We do find that the short-term trading volume increases as the tick size decreases, in contrast to the study of Graham, Michaely and Roberts (2003).

On average, the turnover ratios are $12.47 \%$ higher than normal on the ex-split day during the $1 / 8$ th era, but it is insignificant. The abnormal 
Table 5. Cumulative abnormal volume around the ex-split day for NYSE-listed stocks by era, 1996-2002.

This table presents the (cumulative) abnormal volume surrounding the executions of 724 stock splits from 1996 to 2002 according to the different price-quoting eras. The $1 / 8$ th era extends from January 1 , 1996 to May 6, 1997, the 1/16th era from June 24, 1997 to August 26, 2000, and the decimal era from January 29, 2001 to December 31, 2002. The abnormal volume on event day $t$ is defined as the ratio of turnover (volume/shares outstanding) on day $t$ to normal turnover, where normal turnover is computed as the average turnover during the 80 days surrounding each 11-day ex-split day window. The cumulative abnormal volume is the sum of the abnormal volumes up to and including that day. "***", "*** and "**" denote significance levels of $1 \%, 5 \%$ and $10 \%$, respectively, for the $t$-test.

\begin{tabular}{cccc}
\hline & $\begin{array}{c}1 / 8 \text { th Era } \\
(1996 / 01 / 01-\end{array}$ & $\begin{array}{c}1 / 16 \text { th Era } \\
(1997 / 06 / 24-\end{array}$ & $\begin{array}{c}\text { Decimal Era } \\
(2001 / 01 / 29\end{array}$ \\
Event Day & $1997 / 05 / 06)$ & $2000 / 08 / 26)$ & $2002 / 12 / 31)$ \\
\hline Panel A: Abnormal Volume & & \\
-5 & 0.0398 & 0.0559 & 0.1101 \\
-4 & -0.0669 & -0.0043 & 0.0299 \\
-3 & -0.0427 & $0.0907^{*}$ & 0.0088 \\
-2 & 0.0307 & 0.0092 & 0.0928 \\
-1 & 0.0570 & 0.0807 & $0.1742^{*}$ \\
0 & 0.1247 & $0.1472^{* * *}$ & $0.3020^{* *}$ \\
1 & 0.0130 & $-0.0703^{* *}$ & 0.0253 \\
2 & 0.0555 & 0.0299 & 0.0890 \\
3 & $-0.1242^{* * *}$ & -0.0178 & $-0.0817^{* *}$ \\
4 & -0.1039 & 0.0045 & 0.0242 \\
5 & -0.0523 & 0.0040 & -0.0816 \\
Panel B: Cumulative Abnormal & Volume & \\
$(-1,0)$ & 0.1817 & $0.2279^{* * *}$ & $0.4762^{* *}$ \\
$(0,1)$ & 0.1376 & 0.0769 & $0.3273^{*}$ \\
$(-1,1)$ & 0.1946 & 0.1576 & $0.5015^{*}$ \\
$(-2,2)$ & 0.2808 & 0.1967 & $0.6828^{*}$ \\
\hline
\end{tabular}

turnover ratios become significantly positive during the later two quoting regimes with lower tick sizes. They are $14.72 \%$ during the $1 / 16$ th era, and $30.20 \%$ during the decimal era. Our results are consistent with Stickel (1991) and Michaely and Murgia (1995), who find that stocks with lower transaction costs have ex-day abnormal returns that are close to zero and significantly positive abnormal volume on the ex-day and the day before the ex-day.

The volume results imply that higher bid-ask spreads do impair the ex-split short-term trading in the $1 / 8$ th era, because in both the $1 / 16$ th and 
the decimal eras, the short-term abnormal volume increases. These results are consistent with Hypothesis 2.2.

\section{Conclusion}

The ex-dividend day stock price adjustment in the US and other countries has been commonly interpreted as reflecting taxes. Yet a similar pricing effect is found on the ex-split day, where there are no relevant taxes faced by traders. Market microstructure or nontax market frictions, such as transaction costs, may also contribute to the phenomenon. By examining the ex-split day stock price movements both before and after the NYSE switched to the $1 / 16$ th and the decimal quoting systems, we provide direct evidence of the effect of a change in the minimum tick size on the ex-split day price behavior.

We find that the abnormal ex-split day returns decrease and the abnormal trading volume increases in the $1 / 16$ th and decimal pricing eras, relative to those in the $1 / 8$ th era. Such results support the microstructure-based explanation that declines in the minimum tick size and associated reductions in the bid-ask spread should decrease the average ex-day abnormal returns. Our findings are also consistent with the short-term trading argument. In essence, the microstructure-induced abnormal returns may attract short-term traders into the market.

However, as Kalay (1982) and Miller and Scholes (1982) point out, transactions costs make certain dynamic tax arbitrage strategies too expensive to implement. We find that short-term traders who trade around the ex-split day may be hampered by larger transaction costs during the $1 / 8$ th quoting system. Following the recent switch to the decimal pricing system, which significantly decreases transaction costs through smaller tick sizes and bid-ask spreads, we find that the ex-day abnormal returns have disappeared. Positive abnormal volume around the ex-day following decimalization provides further evidence of short-term trading before stock splits.

To sum up, our evidence of market reactions on the ex-split day supports the hypothesis that the price movements surrounding the split execution stem from the microstructure effects, a phenomenon which becomes weaker after decimalization. It is also consistent with the hypothesis that short-term traders perform arbitrage activities before the ex-split date when transaction costs become lower after decimalization. 


\section{Acknowledgments}

We would like to thank an anonymous referee for helpful comments and suggestions. Robin K. Chou gratefully acknowledges funding from the National Science Council of Taiwan (NSC91-2416-H-008-014).

\section{References}

Bali, R and GL Hite (1998). Ex-dividend day stock price behavior: Discreteness or tax-induced clienteles? Journal of Financial Economics, 47, 127-159.

Bollen, NPB and RE Whaley (1998). Are "teenies" better? Journal of Portfolio Management, 25, 10-24.

Conrad, JS and R Conroy (1994). Market microstructure and the ex-date return. Journal of Finance, 49, 1507-1519.

Dhatt, MS, YH Kim and S Mukherji (1997). Did the 1986 tax reform act affect market reactions to stock splits? A test of the tax-option hypothesis. The Financial Review, 32, 249-271.

Dubofsky, DA (1992). A market microstructure explanation of ex-day abnormal returns. Financial Management, 32-43.

Eades, KM, PJ Hess and EH Kim (1984). On interpreting security returns during the ex-dividend period. Journal of Financial Economics, 13, 3-34.

Fama, EF and KR French (1993). Common risk factors in the returns on stocks and bonds. Journal of Financial Economics, 33, 3-56.

Gibson, S, R Singh and V Yerramilli (2003). The effect of decimalization on the components of the bid-ask spread. Journal of Financial Intermediation, 12, 121-148.

Graham, JR, R Michaely and MR Roberts (2003). Do price discreteness and transactions costs affect stock returns? Comparing ex-dividend pricing before and after decimalization. Journal of Finance, 58, 2611-2636.

Grinblatt, MS, RW Masulis and S Titman (1984). The valuation effects of stock splits and stock dividends. Journal of Financial Economics, 13, 461-490.

Jakob, K and T Ma (2004). Tick size, NYSE rule 118, and ex-dividend day stock price behavior. Journal of Financial Economics, 72, 605-625.

Kadapakkam, P-R (2000). Reduction of constraints on arbitrage trading and market efficiency: An examination of ex-day returns in Hong Kong after introduction of electronic settlement. Journal of Finance, 55, 2841-2861.

Kalay, A (1982). The ex-dividend day behavior of stock prices: A re-examination of the clientele effect. Journal of Finance, 37, 1059-1070.

Karpoff, JM and RA Walkling (1988). Short-term trading around ex-dividend days: Additional evidence. Journal of Financial Economics, 21, 291-298.

Lakonishok, J and T Vermaelen (1986). Tax-induced trading around ex-dividend days. Journal of Financial Economics, 16, 287-319. 
Lamoureux, CG and P Poon (1987). The market reaction to stock splits. Journal of Finance, 42, 1347-1370.

Maloney, MT and JH Mulherin (1992). The effects of splitting on the ex: A microstructure reconciliation. Financial Management, 21, 44-59.

Michaely, R and M Murgia (1995). The effect of tax heterogeneity on prices and volume around the ex-dividend day: Evidence from the Milan Stock Exchange. Review of Financial Studies, 8, 369-399.

Miller, MH and MS Scholes (1982). Dividends and taxes: Some empirical evidence. Journal of Political Economy, 90, 1118-1141.

Shaw, WH (1991). An examination of ex-dividend day stock price movements: The case of nontaxable Master Limited Partnership distributions. Journal of Finance, 46, 755-771.

Stickel, SE (1991). The ex-dividend behavior of nonconvertible preferred stock returns and trading volume. Journal of Financial and Quantitative Analysis, $26,45-61$.

Woolridge, JR (1983). Ex-date stock price adjustment to stock dividends: A note. Journal of Finance, 38, 247-255. 